\title{
Computers and Teaching: Evolution of a Cyberclass
}

\author{
Jerome Young, University of Arkansas at Monticello
}

$D^{\text {is }}$ uring the last few years, academics have been bombarded with information relating to the tremendous growth in information technology and with conjecture-some purely speculative, some solidly groundedabout how this growth in information technology is going to affect the way we teach. Numerous publications foretell of changing teaching paradigms, from options for delivery of information to students to whole new ways of structuring higher education, in order to take advantage of technological advances and turn them to the advantage of higher education as a whole (American Association of State Colleges and Universities 1995; Hunter 1996).

With the advent of distance learning, utilization of super-fast telephony, means for compressing audio and video signals to deliver classes to students who may never come on campus to take courses, and the use of computers and the Internet for two-way communication between professors and students, there are some who suggest that technology will eventually lead to the enrichment, if not the replacement, of the traditional student-professor relationship. Further, there have been suggestions that the "Carnegie Unit" (i.e., fifty-five minutes of in-class instruction per credit hour) may soon give way to "computer-assisted distance learning" (Reid 1997). This has led some members of the professorate to become alarmed that technology may replace the all-important human element in the student-professor relationship.

However, the growth of computerized delivery of information affords

Jerome Young is associate professor of political science at the University of Arkansas at Monticello, where he has been teaching a variety of political science courses for the past eleven years. His web address is www. vamont edu/ young/. the professor an unprecedented opportunity to take advantage of technology to greatly enhance his or her traditional role as mentor, guide, source of knowledge, and authority. Moreover, introducing students to the tools necessary for learning new skills and performing future work is an important part of the professor's responsibilities.

Certainly, most universities have realized the potential for using computers as teaching aids; it would be difficult to find a university that did not have several computer labs for students and computer access for faculty. In the case of my own university (enrollment approximately 2,000 ), more than 260 computer terminals are available in on-campus labs and dormitories for student use. Furthermore, every faculty member who wants one has a computer that, along with student terminals, is wired via fiberoptic cable to the main university computer. In addition, the university tries very hard to keep software such as word processors, spreadsheets, and database programs as up to date as possible. All faculty, staff, and students have access to the Internet and, via constantly updated browsers, the World Wide Web.

The opportunity definitely exists for professors to make the computer an important part of student learning. That the use of computers should be a necessary skill for students is discussed very widely in the worlds of business and academe. Countless articles in print and on the Internet discuss this very topic. Steve Moore of the Cato Institute pointed out particularly clearly the necessity of making computer skills a part of a student's college education during an NPR interview. Referring to worker productivity and capital investment in technology, he stated, "a worker that works with a computer in front of them $[$ sic $] \ldots$ is going to on average earn about $\$ 10,000$ to $\$ 20,000$ more a year than a worker that does not have that computer in front of them [sic]." In the same discussion, Jim Smith, an economist for the Rand Corporation remarked, "The market is screaming as loud as it can scream, 'get skills, get skills.' It can't say it any louder than that, right?" (Edwards 1996).

Indeed, many professors are now making the computer an integral part of teaching, either as an in-class aid itself, or by requiring use of the Internet to access information, facilitate discussion, send and receive assignments, and so forth.' Available on the Internet alone are countless suggestions for using the web as a teaching aid and even templates for course pages that professors can download and use to construct syllabi. ${ }^{2}$

The task of writing one's own web page has been simplified with the proliferation of HyperText Markup Language (HTML) editing programs. It is no longer necessary to learn HTML well in order to publish one's own original web pages (Gizzi 1996). Definitions for important Internet terms are provided in Table 1.

Use of the Internet as a teaching aid is literally exploding. However, until lately, many of us did not start to use cyberclasses as a means to teach students the necessary computer skills mentioned above. Until about three years ago, I required only that my students use a computer to write their research papers (I required that the papers be printed on a dot matrix printer). When my university added more computer labs, connected more machines to the Internet, and constructed a campus network using fiber optics, I realized that email was rapidly replacing telephone calls and surface mail (paper memos). It was then that I felt it would be necessary for my students to learn how to 
communicate via the Internet. To that end, I began to require that all my students acquire a university computer account and use email. Extra credit was given for simple exercises using the Internet. Study guides were distributed via email. At the same time, I had begun to "surf the net," and as the WWW began to develop, it became apparent to me that the web was becoming a tremendous information resource that could be used in conjunction with library research to produce better research papers.

Then, after attending a workshop on programing HTML conducted by our Computer Services Department, I took my first tentative steps toward creating a cyberclass. At first, my efforts involved writing a rudimentary personal web page that had a few links to research sources, some contacts and personal information, and little else. I found writing HTML fun, experimented with several efficient HTML editor programs that greatly simplify the task of using HTML, and I began to expand my personal page. It became a starting point leading to other pages including a Politics and Political Science page (www.uamont.edu/ young/pps. html), which includes a growing number of links to general research sources and to specific sources tailored to meet the research needs of students in my classes.

Finding and choosing appropriate research links has proven to be a different matter. The information published on the web has increased to such a degree that it can (and should) take hours to search for and sort through promising links. Morever, new links are always appearing, and constant updating is beneficial, if not necessary.

It is at this point, providing some directions to useful web sites, that the contribution of the professor is absolutely necessary for students. It would be less than helpful, if not actually harmful, to simply suggest a few search engines or general sites and tell students to research a topic and then write a paper. Those who have conducted web searches know that finding quality sites is a long, difficult process of weeding out sources, not unlike conducting library searches. The least instructors should do, if they are going to require some Internet research of their students, is to find some sites that are good starting points. Faculty can use their advanced training and knowledge of the subjects to be researched to find appropriate sites and present specific URLs to students so they avoid spending hours visiting sites that "look good" but actually are inappropriate or even misleading.

Once I decided to maintain the political research page to the best of my ability and within the limits of available time, the next steps toward creating a cyberclass proved to be relatively simple. Our Computer Service Department helped set up class listservs for class discussions and assignments and an FTP site students can use to upload research papers into the university main computer. I monitor the listserv discussions and look for "teaching opportunities," points in the exchange where it appears students poorly understand what they are discussing or when their ideas need clarification or guidance. Later, these subjects are explored in class, either by lectures and/or further class discussion.
For research papers, I require students to prepare them using one of the leading word-processing programs and to password protect their files. File names are standardized and include the student's last name and a code indicating the assignment (e.g., lastname pa1). Students' passwords are the last five digits of their social security numbers. Students use FTP to upload their papers to a class folder where I can access them, download them onto my computer, grade them, rename and password protect them, and upload the graded papers for the students to download later.

The next step in the evolution of my cyberclasses involved publishing a "Courses Taught" page and linking it to my personal web page. The Courses Taught page (www.uamont. edu/ young/courses.html) has links to the syllabi for all the courses that I teach. In addition to the traditional syllabus information, these pages have links to other information and research sources. Although I pass out syllabi for the larger introductory classes, because students can severely strain lab printer capabilities making hard copies from the web site, I no longer pass out syllabi on the first day of class for my smaller

\section{TABLE 1 \\ Common Internet Terms}

\section{DEFINITIONS}

HTML Hyper Text Mark-up Language, a programming code used to write web pages.

Cyberclass The term can cover any method of using the Internet for teaching, ranging from simply making information available on an electronic syllabus to teaching an entire class online (Klass 1996). I prefer to define a cyberclass as one in which, at minimum, the syllabus is accessible electronically, research links are provided in the syllabus, and some form of electronic discussion/participation is required.

Listserv A type of program that allows anyone who has subscribed to a list to send email and receive it from everyone else on the list.

FTP File Transfer Protocol. Software that allows one to upload or download files from one computer to another.

Factoid Something that is not quite a fact; akin to a "sound bite" in TV parlance.

URL Uniform Resource Locator. The actual address of a page on the World Wide Web. 


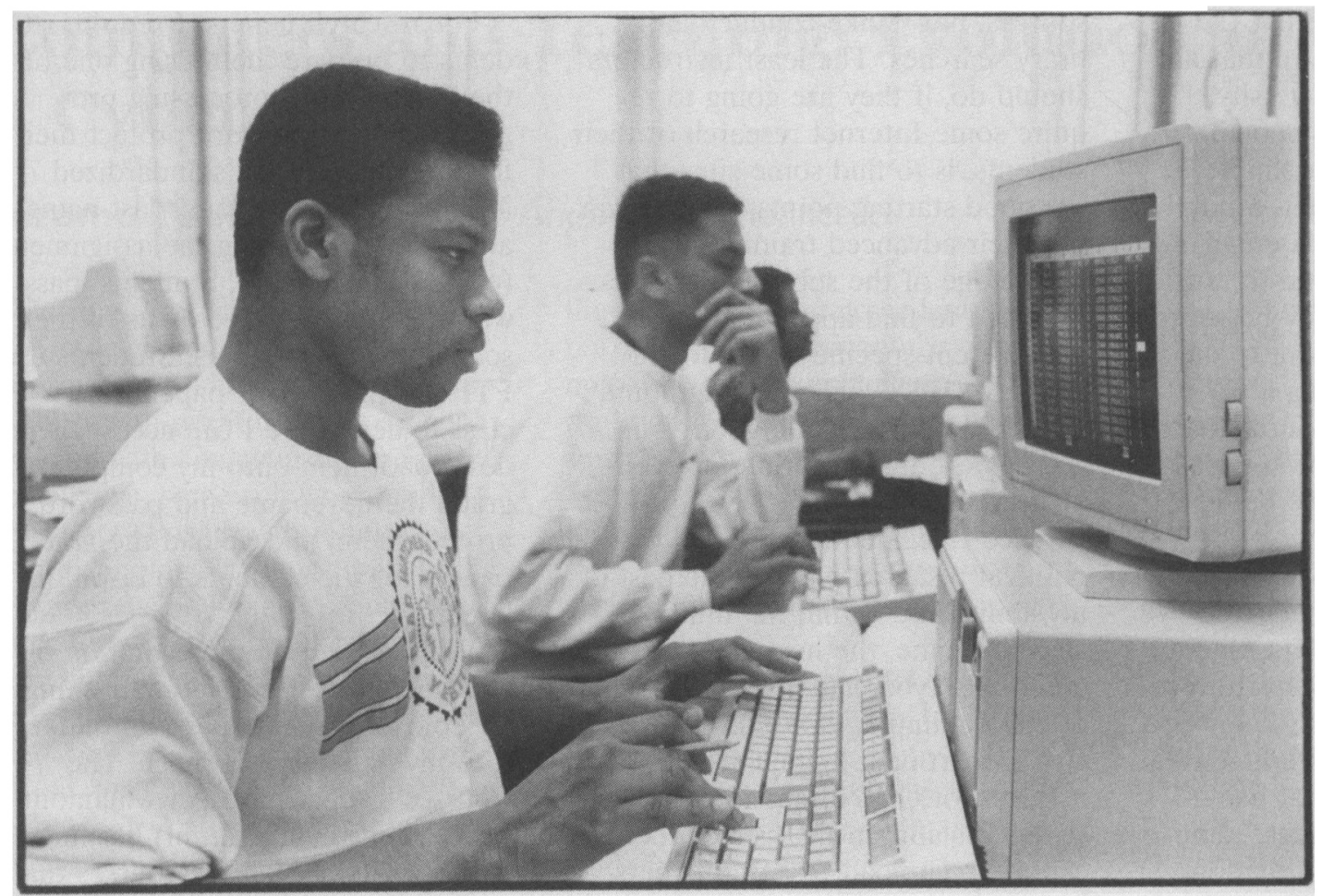

Photo courtesy of Rutgers University

(less than 20 students) classes. Instead, I give students a single sheet of instructions on how to acquire an account on the university computer, how to find the course syllabus, and how to print it. Students are required to complete that assignment within three days (the reading assignments for the first few class meetings are included in the handout.)

Students' reactions to the above course changes have been, on the whole, positive. Particularly popular were the listserv discussions and Internet research assignments. Somewhat less popular has been the required use of FTP to upload and download papers. The main reason for the latter development is that, although many students are fairly well versed in word-processing techniques and have little trouble finding research sources starting from the links that have been provided for them, their overall computer knowledge is still somewhat "spotty." Not all college students are computer literate. ${ }^{3}$ For example, in one of my advanced classes in which papers had to be transferred via FTP, the students had some difficulty in completing the assignment properly.
Based on that experience, it appears that a one-credit course on doing social science research on the Internet would be helpful. Requiring completion of such a course would be one way to ensure that students' computer knowledge would be adequate to proceed to the next step in developing cyberclasses.

The next (and probably not last) step in developing cyberclasses is authoring course pages for classes to be taught entirely in cyberspace. These courses will most likely be appropriate for only the most advanced undergraduate students and graduate students. Only minimal, if any, classroom attendance would be required. So far, I intend to offer, as an experiment, only one such course for advanced, upper-division undergraduate or graduate students who have demonstrated that they have the technical competency to handle such a course. A few such students are taking regular courses in this way now, especially where there is some compelling reason that they cannot come to the campus regularly.

But having come this far in the evolution of cyberclasses, I have begun to reflect on just what it is that I am trying to do and if it is feasible. As noted above, the technological means are available and the necessity for students to acquire technological skills is more than apparent. However, just what is the role of the professor in this massive development of technology and what is it that professors are supposed to pass on to their students? I still believe, as I argued above, that professors should make acquisition of advanced computer skills a part of their teaching methods. But I have also come to believe that "get skills, get skills" means much more than teaching students how to use a computer to amass mounds of data.

Having learned how to get at those data, just what is a student to do with them? As Joel Achenbach (1995) has pointed out, it is more difficult today than ever to distinguish facts from non-facts or "factoids." This is where the professor needs to facilitate the learning process. He or she needs to help students learn how to recognize what 
facts are and how to organize and analyze them. Without that ability, no matter how well a student can search databases, use FTP, communicate via email, or make web pages, all he or she has learned is the manipulation of some software tools, not how to formulate ideas using those tools ("Not Virtually Assured" 1996).

Once students have learned how to access data and sift out the facts, merely possessing facts is not equal to "knowing."4 Producing students capable of converting a mass of facts into knowledge goes to the very core of what instructors hope to accomplish. Most faculty have spent a great part of their lives learning how to distinguish facts from non-facts and how to organize, categorize, analyze, and synthesize those facts to produce insights and knowledge.

The human element in the studentprofessor relationship is crucial for developing the skills needed to interpolate data gathered. The speed and impersonality of computer-assisted learning removes much of the nonverbal communication and spontaneity that take place in human interaction. Even the advent of video conferencing does not completely remove the physical and psychological distance between participants at the different sites. Faceto-face interaction is indispensable for developing oral communication and cooperative and leadership skills. And, cooperative learning and group sessions are invaluable in facilitating the learning process.

\section{Notes}

1. While doing research for this article, I found dozens of courses (e.g., Ho 1996) that, to one degree or another, involve use of the computer both inside and outside the classroom. For an example of in-class use, see Ellingson (1996). For use of the Internet as a teaching tool or teaching aid, see Kinley and Toney (1996).

2. Two particularly useful publications are "A Survey of Political Science Cyberclasses," a paper written for the APSA Computers and Multi-
Rather than fearing that a tendency to consider surfing the Internet will replace in-depth study of books and use of other library resources (Himmelfarb 1997), instructors should realize that students can keep abreast of developments before publications are forthcoming.

Some students develop the self-discipline necessary for learning, in whatever context, because the professor asks questions face-to-face. More selfdiscipline is required when the professor is removed from the student. Some students will find that self-learning is too difficult or frustrating for them (Reid 1997). Also, many professors may be concerned about the security of testing. This problem can be solved using existing technology or simply by requiring visits to the classroom for tests.

Also, there are technical problems that need to be addressed before making a decision to fully convert to computer-assisted distance learning via the Internet. An important, though decreasing, concern is cost. Although universities are rapidly upgrading computer technology on campus, computer-assisted distance learning relying exclusively on the Internet would most likely require the purchase of additional software and modems. For the student, extra costs could be high, considering the price of purchasing a home computer (buying a reasonably up-to-date computer should be a very high priority for students), buying soft- ware, and the expense of paying for Internet access if it isn't supplied by the university. Although an added financial burden, especially for students, bearing these costs is necessary.

Despite the validity of these concerns, professors need to be in the forefront of helping students develop their technological competency. It would be disastrous if such development were left in the hands of those whose "bottom line" approach to education is the highest number of students graduated at the least cost and who often disregard many of the intangibles involved in the educational process. The very heart of education itself might be threatened. Imagine an educational system which emphasized tools and neglected the substance of the educational process.

What we are faced with today is the on-going development of a super-sophisticated set of tools and the availability of an astronomically large amount of data that is, at best, only poorly organized. The challenge before professors and students alike is much the same as it has always been. What has changed is the scope of the task. It is continuing to expand exponentially. We all need to continue sharpening our abilities to discriminate, categorize, and analyze, and, at the same time, developing our ability to use technology, to provide basic tools that will help us meet the challenge of learning and producing knowledge about the world around us. media section (Klass 1996), and "Virtual Classroom" (Kinley and Toney 1996), which has templates that can be downloaded and converted to web pages.

3. It would be very useful to be able to refer to an empirical study that addresses the variation of students' advancement in terms of their computer knowledge, especially one that addresses this kind of variation among universities of different sizes and in different locations. In my own case, my university is rural, with open enrollment, and has a student population of about 2000. Therefore, I assumed that my students were not very advanced in using computers and, as a consequence, I tested and retested each Internet element several times before I made it part of a course.

4. For a good, brief discussion of this point, see Chaska (1996). 


\section{References}

Achenbach, Joel. 1996 "You Can't Believe Everything You Read." Washington Post, December 4, sec. C.

American Association of State Colleges and Universities. 1995. On the Brink: Report on the Use and Management of Information Technology at AASCU Institutions. Washington, DC.

Chaska, Jonathan. 1996. Information or Knowledge? (Available online: http://totalnews.com/ gc102096.html).

Edwards, Bob. 1996. "The Growing Inequality of Incomes in America, Part 4." NPR's Morning Edition. (Available online: www. npr.org/plweb-cgi/fastweb?getdoc + npr + npr + $613+4+w A A A+w A A A+$ income\%26inequality \%26 part \%264).

Ellingson, Tracy. 1996. "Professor Steven Smith Takes Political Science Online." CLA Today 18(2):6.

Gizzi, Michael C. 1996. A Primer on the World Wide Web in the Political Science Classroom. (Available online: www.apsanet.org/ $\sim \mathrm{cms} /$ primer/).

Himmelfarb, Gertrude. 1997. "Revolution in the Library." The American Scholar 66:197-204.

Ho, Karl. 1996. Political Science Cyberclasses. (Available online: www.psci.unt.edu/kho/ cybercls/index.htm).
Hunter, Donna. 1996. cybercolleges. (Available online: www.cnet.com/Content/Tv/CNETCentral/ Links/colleges.html).

Kinley, Ed, and Terry Toney. 1996. Virtual Classroom. (Available online: www.enmu. edu/virtual/virt.html).

Klass, Gary. 1996. A Survey of Political Science Cyberclasses. (Available online: www.ilstu. edu/depts/polisci/apsa96/roundtab.htm).

"Not Virtually Assured." 1996. The Salt Lake Tribune, February 7, sec. A.

Reid, John E. Jr. 1997. "Preparing Students For the Task of Online Learning." Syllabus 10(7): $38-39$.

\section{$\widehat{\text { AED }}$.}

The Academy for Educational Development announces the

\section{National Security Education Program 1999 GRADUATE INTERNATIONAL FELLOWSHIPS COMPETITION}

National Security Education Program (NSEP) Graduate International Fellowships enable U.S. graduate students to pursue specialization in area and language study or to add an important international dimension to their education. Created by Congress to address the need to increase the ability of U.S. citizens to communicate and compete globally, the NSEP embodies a recognition that the scope of national security has expanded to include not only the traditional concerns of protecting and promoting American well-being, but the new challenges of global society, including: sustainable development, environmental degradation, global disease and hunger, population growth and migration, and economic competitiveness.

NSEP fellowships are intended to provide support through overseas study and limited domestic tuition to students who will pursue the study of languages, cultures, and world regions deemed critical to U.S. national security. Excluded explicitly is study of Western Europe, Canada, Australia, and New Zealand. Fellowships are awarded in a broad range of academic and professional disciplines including business, economics, history, international affairs, law, applied sciences and engineering, health and biomedical sciences, political science, and other social sciences. Award recipients incur a requirement to work for an agency of the federal government involved in national security affairs or in the field of higher education in an area for which the fellowship was awarded, in that order of precedence.

Eligibility Requirements: Applicants must be U.S. citizens, enrolled in or applying to graduate programs in accredited U.S. colleges or universities located within the United States. All applications must include formal study of a modern language other than English.

To Apply: Guidelines and application forms for NSEP Graduate International Fellowships may be obtained from our Web page at http://www.aed.org/nsep. They also may be obtained by contacting AED at 800-498-9360 or 202-884-8285, or by e-mail at nsep@aed.org. Deadline: Applications must be postmarked by January 15, 1999. No faxed submissions accepted; late applications will not be reviewed. 